\title{
The effect of changing arterial blood pressure and carbon dioxide on cerebral blood flow
}

\author{
Jean Claude Baron
}

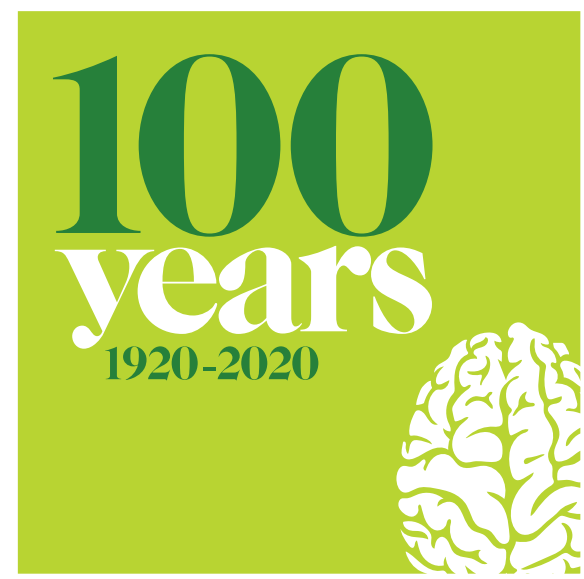

The short article entitled 'Effect of alterations in the arterial carbon dioxide tension on the blood flow through the cerebral cortex at normal and low arterial blood pressures', published in 1965 in the JNNP by A Murray Harper and HI Glass, ${ }^{1}$ is among the most cited articles ever published in the journal (429 citations as of 21 January 2020). Interestingly, the same first author published the subsequent year in the JNNP another highly cited article $^{2}$ on a closely related subject (372 citations as of 2020).

The Harper and Glass 1965 article was the first to assess the effects of changes in the arterial partial pressure of $\mathrm{CO}_{2}$ $\left(\mathrm{PaCO}_{2}\right)$ on the cerebral circulation in conditions of normal arterial blood pressure, moderate hypotension and severe hypotension. To this end, the authors applied in anaesthetised mongrel dogs the technique that Lassen and Ingvar had just developed to measure quantitative regional blood flow of the exposed cerebral cortex using radioactive krypton injected in the internal carotid artery. ${ }^{3}$

The strong effects of changes in $\mathrm{PaCO}_{2}$ on the cerebral vasculature, first discovered in 1928 by Forbes and Wolff via direct observation of the pial arteries through a glass window in animals, was subsequently confirmed in humans, first indirectly by

Neurology, Hopital Sainte-Anne, Paris CB2 2QQ, France

Correspondence to Professor Jean Claude Baron, Neurology, Hopital Sainte-Anne, Université de Paris, Inserm U1266, Paris 75014, France; jean-claude. baron@inserm.fr
The effect of changing arterial blood pressure and carbon dioxide on cerebral blood flow

Authors: Harper AM, Glass HI

Year Published: 1965

Number of times cited: 548

Lennox and Gibbs in $1932^{4}$ by means of jugular vein $\mathrm{PO}_{2}$ measurements, and then directly by Kety and Schmidt ${ }^{5}$ in 1946 using their whole-brain cerebral blood flow (CBF) technique that used inhaled $\mathrm{N}_{2} \mathrm{O}$. These studies established that hypercapnia is the most potent brain vasodilator, and conversely hypocapnia a very potent vasoconstrictor. In 1964, Reivich ${ }^{6}$ documented in monkeys that hypercapnic vasodilation, and hence the CBF increase, reached a plateau around $150 \mathrm{~mm} \mathrm{Hg}$ $\mathrm{PaCO}_{2}$, and conversely that vasoconstriction was maximal for $\mathrm{PaCO}_{2}$ levels around $18 \mathrm{~mm} \mathrm{Hg}$. In parallel, Fog, Forbes and others, using the glass window approach, showed in the 1930s that reductions in mean arterial blood pressure induced pial artery vasodilatation, and conversely, that is, the cerebral auto-regulation. ${ }^{2}$

In their seminal 1965 JNNP article, Harper and Glass ${ }^{1}$ aimed to assess whether the vasodilation induced by hypotension affected the cerebrovascular response to changes in $\mathrm{PaCO}_{2}$. They indeed found that, as compared with the normotensive condition, the slope of the CBF response to $\mathrm{PaCO}_{2}$ changes was shallower at moderate arterial hypotension, and completely flat at severe hypotension levels (figure 1), documenting that the same resistive pial vessels were involved in the two regulations, and that maximal vasodilation/vasoconstriction in response to changes in one physiological variable abolished the response to the other physiological variable.

Why has this paper been, and still is-28 citations since 2016-so widely cited? First of all, it describes a key physiological phenomenon that has wide implications in animal and human cardiovascular and respiratory physiology and pharmacology. Second, Harper and
Glass' observations have major clinical implications in numerous medical disciplines, particularly neuro-anaesthesia, neuro-intensive care and, of course, cerebrovascular diseases-specifically, that, on top of $\mathrm{PaO}_{2}$, both blood pressure and $\mathrm{PaCO}_{2}$ have to be closely monitored and controlled to avoid worsening of the already present brain damage. For instance, in acute traumatic brain injury with threateningly elevated intra-cranial pressure (ICP)—which causes maximal vasodilation, further increasing the ICP in a vicious cycle-brief hypocapnia can be life-saving by rapidly reducing the cerebral blood volume.

In clinical neurology and stroke medicine, the implications of the concept of maximal vasodilation has had to this day major impact in the understanding and management of cerebrovascular diseases including transient ischaemic attacks (TIAs) and acute ischaemic stroke. Indeed, thanks to the development of non-invasive techniques to measure regional $\mathrm{CBF}$ and oxygen metabolism in man using positron emission tomography, it was shown that in a subset of patients with repeated TIAs affecting the territory of an occluded or severely stenotic internal carotid artery, there was permanent hypoperfusion in the distal cortical areas associated with increased oxygen extraction fraction, documenting exhausted vasodilatory reserve in turn causing clinical symptoms on a haemodynamic - as opposed to embolic-basis. ${ }^{8}$ Subsequently, Lassen and co-workers developed a pharmacological vasodilatation challenge using acetazolamide (Diamox) to test the cerebral vasodilatory reserve, also called cerebrovascular reactivity (CVR), ${ }^{9}$ an approach still in use today using single-photon emission computed tomography and perfusion radiotracers such as $99^{\mathrm{m}} \mathrm{Tc}-\mathrm{HMPAO}$ (hexamethylpropylene amine oxime). Transcranial Doppler ultrasound using the breath holding test is also routinely used worldwide to assess the CVR distal to, and hence the haemodynamic effects of, carotid stenosis or occlusion. ${ }^{10}$ More recently, MRI-based or CT-based perfusion imaging has been used to map impaired CVR across the whole brain in the form of 
A

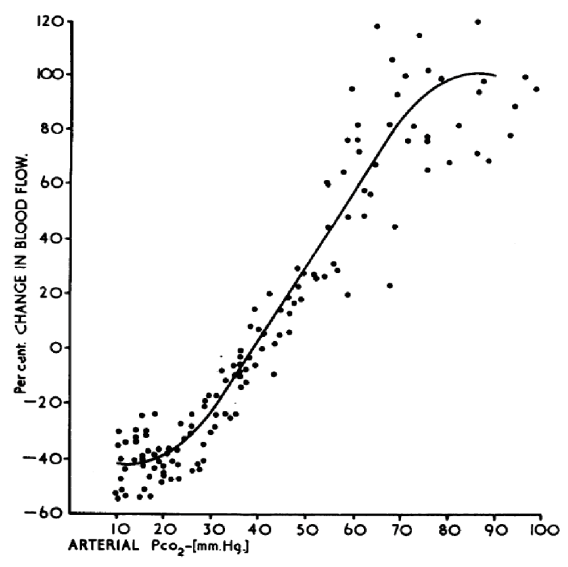

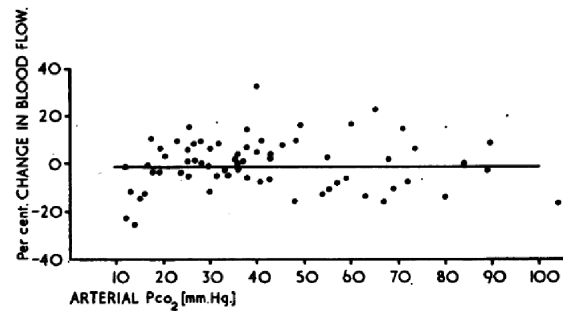

Figure 1 The relationship between cerebral blood flow and $\mathrm{PaCO}_{2}$ (range: 10-100 mm Hg) at normotension ( $A$; mean arterial blood pressure $=150 \mathrm{~mm} \mathrm{Hg}$ ) and at marked hypotension ( $B$; mean arterial blood pressure $=50 \mathrm{~mm} \mathrm{Hg}$ ) in mongrel dogs (reprinted from Harper and $\mathrm{Glass}^{1}$ ). $\mathrm{PaCO}_{2}$, arterial partial pressure of $\mathrm{CO}_{2}$.

prolonged arterial mean transit time under physiological conditions, ${ }^{11}$ currently the most widely used approach to determine optimal medical and/or surgical management of such patients. Novel, completely non-invasive MR-based approaches, not as yet fully implemented in routine, involve inhaled $\mathrm{CO}_{2}$ challenge using blood oxygenlevel dependent MRI or arterial spin labelling. ${ }^{12}$

Regarding acute ischaemic stroke (AIS), the concept of maximal vasodilatation also had important implications. First of all, it made the old idea of treating AIS patients with pharmacological vasodilators not only obsolete, but also potentially hazardous, because inducing vasodilation in the non-maximally vasodilated territories involves a risk of diverting blood flow away from the ischaemic areas (so-called 'Robin Hood syndrome', or 'haemodynamic steal'), ${ }^{13}$ an effect also well documented in chronic carotid occlusion. ${ }^{14}$ Lassen's group subsequently tested 'inverse steal'-that is, they assumed that reducing perfusion in unaffected areas by means of hyperventilation would elevate perfusion in ischaemic areas- but unfortunately this approach failed to show clinical benefit. ${ }^{15}$ Second, the concept of maximal vasodilation pointed to the potential risk of worsened ischaemia associated with drops in systemic blood pressure, a variable now closely monitored and controlled in AIS. ${ }^{16}$
To sum up, Harper and Glass' widely cited physiology paper reporting results from animal experiments 55 years ago in the JNNP has contributed to major advances in understanding the disorders of the cerebral circulation involved in numerous neurological and neurosurgical conditions, and in turn has impacted to the present day the management of the afflicted patients.

Contributors I have written this editorial comment by myself, and am the sole responsible for its contents.

Funding The authors have not declared a specific grant for this research from any funding agency in the public, commercial or not-for-profit sectors.

\section{Competing interests None declared.}

Patient consent for publication Not required.

Provenance and peer review Commissioned; internally peer reviewed.

(C) Author(s) (or their employer(s)) 2020. No commercial re-use. See rights and permissions. Published by BMJ.

$$
\text { (D) Check for updates }
$$

To cite Baron JC. J Neurol Neurosurg Psychiatry Epub ahead of print: [please include Day Month Year]. doi:10.1136/jnnp-2019-322432

Received 28 January 2020

Revised 13 February 2020

Accepted 9 March 2020

J Neurol Neurosurg Psychiatry 2020;0:1-2. doi:10.1136/jnnp-2019-322432

\section{REFERENCES}

1 Harper AM, Glass HI. Effect of alterations in the arterial carbon dioxide tension on the blood flow through the cerebral cortex at normal and low arterial blood pressures. I Neurol Neurosurg Psychiatry 1965:28:449-52.

2 Harper AM. Autoregulation of cerebral blood flow: influence of the arterial blood pressure on the blood flow through the cerebral cortex. I Neurol Neurosurg Psychiatry 1966;29:398-403.

3 Lassen NA, Ingvar DH. The blood flow of the cerebral cortex determined by radioactive krypton. Experientia 1961;17:42-3.

4 Lennox WG, Gibbs EL. The blood flow in the brain and the leg of man, and the changes induced by alteration of blood gases. J Clin Invest 1932;11:1155-77.

5 Kety SS, Schmidt CF. The effects of active and passive hyperventilation on cerebral blood flow, cerebral oxygen consumption, cardiac output, and blood pressure of normal young men 1. J Clin Invest 1946:25:107-19.

6 Reivich M. Arterial Pco2 and cerebral hemodynamics. Am J Physiol 1964;206:25-35.

7 Curley G, Kavanagh BP, Laffey JG. Hypocapnia and the injured brain: more harm than benefit. Crit Care Med 2010;38:1348-59.

8 Baron JC, Bousser MG, Rey A, et al. Reversal of focal "misery-perfusion syndrome" by extra-intracranial arterial bypass in hemodynamic cerebral ischemia. A case study with 150 positron emission tomography. Stroke 1981;12:454-9.

9 Vorstrup S, Brun B, Lassen NA. Evaluation of the cerebral vasodilatory capacity by the acetazolamide test before EC-IC bypass surgery in patients with occlusion of the internal carotid artery. Stroke 1986;17:1291-8.

10 Ratnatunga C, Adiseshiah M. Increase in middle cerebral artery velocity on breath holding: a simplified test of cerebral perfusion reserve. Eur J Vasc Surg 1990;4:519-23.

11 Maeda M, Yuh WT, Ueda T, et al. Severe occlusive carotid artery disease: hemodynamic assessment by $\mathrm{Mr}$ perfusion imaging in symptomatic patients. AJNR Am J Neuroradiol 1999;20:43-51.

12 Liu P, De Vis JB, Lu H. Cerebrovascular reactivity (CVR) MRI with $\mathrm{CO} 2$ challenge: A technical review. Neuroimage 2019;187:104-15.

13 Olesen J, Paulson OB. The effect of intra-arterial papaverine on the regional cerebral blood flow in patients with stroke or intracranial tumor. Stroke 1971;2:148-59.

14 Kuwabara Y, Ichiya Y, Sasaki M, et al. Time dependency of the acetazolamide effect on cerebral hemodynamics in patients with chronic occlusive cerebral arteries. Early steal phenomenon demonstrated by [150] $\mathrm{H} 20$ positron emission tomography. Stroke 1995;26:1825-9.

15 Christensen MS, Paulson OB. Prolonged artificial hyperventilation in severe cerebral apoplexy. Clinical results and cerebrospinal fluid findings in a controlled study. Eur Neurol 1972;8:137-41.

16 Powers WJ, Rabinstein AA, Ackerson T, et al. Guidelines for the early management of patients with acute ischemic stroke: 2019 update to the 2018 guidelines for the early management of acute ischemic stroke: a guideline for healthcare professionals from the American heart Association/American stroke association. Stroke 2019:50:e344-418. 